\title{
Construction and identification of an RNA interference lentiviral vector targeting the mouse TNF- $\alpha$ gene
}

\author{
JIBO WANG ${ }^{1}$, HONGDA LIANG $^{1}$, YINGJIE ZHAO ${ }^{1}$, XIANGPING LIU $^{2}$, KUN YANG $^{2}$ and AIHUA SUI ${ }^{2}$ \\ Departments of ${ }^{1}$ Rheumatology and Clinical Immunology and ${ }^{2}$ Central Laboratory, \\ The Affiliated Hospital of Qingdao University, Qingdao, Shandong 266003, P.R. China
}

Received September 28, 2014; Accepted August 5, 2015

DOI: $10.3892 / \mathrm{etm} .2015 .2813$

\begin{abstract}
The aim of this study was to construct RNA interference (RNAi) lentiviral vector particles targeting the mouse tumor necrosis factor- $\alpha(\mathrm{TNF}-\alpha)$ gene. Three types of small interfering RNA (siRNA) targeting the mouse TNF- $\alpha$ gene were designed, synthesized and transfected into RAW264.7 cells. Screening was performed to identify the siRNA sequence exhibiting the highest inhibition efficiency; based on this, recombinant lentiviral plasmids were constructed and co-transfected into $293 \mathrm{~T}$ cells with packaging plasmids for the production of lentiviral particles. The screening results showed that the TNF- $\alpha$ mRNA expression levels of the three siRNA groups were significantly lower than those of the negative control group, with the highest inhibition rate in the siRNA2 group (83.09\%). Similarly, the expression levels of TNF- $\alpha$ protein in the three siRNA groups were significantly lower than those of the negative control group, and the highest inhibition rate was found in the siRNA2 group $(51.16 \%)$. The mRNA expression of interleukin (IL)-1 $\beta$ and IL-6 showed no significant difference among the siRNA groups and the negative control. The recombinant lentiviral shuttle plasmid was constructed, and electrophoresis revealed the polymerase chain reaction product to be $343 \mathrm{bp}$, while that of the empty vector was $306 \mathrm{bp}$; DNA sequencing showed partial insertion. The virus titer was calculated to be $2 \times 10^{6} \mathrm{TU} / \mu \mathrm{l}$. In conclusion, RNAi lentiviral vector particles targeting the mouse TNF- $\alpha$ gene were successfully obtained in the present study. This method may be used to produce lentiviral vector for the in vivo study of RNAi gene therapy targeting TNF- $\alpha$.
\end{abstract}

Correspondence to: Dr Jibo Wang, Department of Rheumatology and Clinical Immunology, The Affiliated Hospital of Qingdao University, 16 Jiangsu Road, Qingdao, Shandong 266003, P.R. China E-mail: wangjibocn@163.com

Key words: RNA interference, lentiviral vector, macrophages, tumor necrosis factor- $\alpha$

\section{Introduction}

The completion of the Human Genome Project genomic map has led to significant advances in the field of gene therapy, one being the development of RNA interference (RNAi). To implement RNAi, the specific small interfering RNA (siRNA) for the target gene must firstly be designed and synthesized; the oligonucleotide sequence can then be designed and synthesized according to its sequence in order to construct a recombinant lentiviral plasmid-expressing short hairpin RNA (shRNA) $(1,2)$. The selection of the viral vector for the implementation of RNAi is also important. Certain viral vectors used for gene transfer are nonintegrative, whereas others are able to integrate into the host cell chromatin. The most commonly used nonintegrative vectors are derived from adenoviruses, herpes virus or adeno-associated virus. The integrative vectors are derived from type $\mathrm{C}$ retroviruses, such as murine leukemia virus or lentiviruses such as human immunodeficiency virus. Lentiviral vectors are a widely used type of virus vector for studies of gene function and therapy. These vectors can be integrated into the genome of target cells and are associated with a long expression duration, low immunogenicity and low cytotoxicity, meaning that they can be effectively used in cell lines that are considered to be difficult to transfect, including macrophages, neurons and pancreatic cells (3-8). Tumor necrosis factor- $\alpha$ (TNF- $\alpha$ ) is an important proinflammatory cytokine associated with inflammatory arthritis (9) that is involved in the physiopathological process of rheumatoid arthritis. The aim of the present study, therefore, was to construct an RNAi lentiviral vector targeting the mouse TNF- $\alpha$ gene, in order to provide a basis for RNAi gene therapy targeting TNF- $\alpha$.

\section{Materials and methods}

Design and synthesis of siRNA. Based on the mouse TNF- $\alpha$ gene mRNA sequence (NM_013693) in the GenBank database (http://www.ncbi.nlm.nih.gov/genbank/), siRNA was designed accordingtosiRNAdesignprinciples(10)and thesiRNATargetFinder found on the Ambion ${ }^{\circledR}$ (USA) website (https://www.lifetechnologies.com/cn/zh/home/life-science/rnai/synthetic-rnai-analysis. html\#tool).In order to avoid off-target effects (11), the BasicLocal Alignment Search Tool (http://blast.ncbi.nlm.nih.gov/Blast.cgi) was run against the siRNA sequence so that homologous 
Table I. siRNA sequences.

\begin{tabular}{ll}
\hline Name & \\
\hline siRNA1 & Sequence \\
siRNA2 & Sense: 5'-CAGAAAGCAUGAUCCGCGATT-3' \\
& Antisense: 5'-UCGCGGAUCAUGCUUUCUGTG-3' \\
siRNA3 & Sense: 5'-GUGCCUAUGUCUCAGCCUCUUTT-3' \\
& Antisense: 5'-AAGAGGCUGAGACAUAGGCACTT-3' \\
Negative control siRNA & Sense: 5'-GCCGAUUUGCUAUCUCAUATT-3' \\
\hline
\end{tabular}

siRNA, small interfering RNA.

Table II. Sequences of the primers and probes.

\begin{tabular}{|c|c|c|}
\hline Gene & Primers and probes & Annealing temperature $\left({ }^{\circ} \mathrm{C}\right)$ \\
\hline TNF- $\alpha$ & $\begin{array}{l}\text { Forward primer: 5'-TCTTCCCTGAGGTGCAATGC-3' } \\
\text { Reverse primer: 5'-GCTCCGTTTTCACAGAAAACATG-3' } \\
\text { Probe: 5'-(FAM) TGGAGGACCCAGTGTGGGAAGCTGT(TAMRA)-3' }\end{array}$ & 62 \\
\hline IL-1 $\beta$ & $\begin{array}{l}\text { Forward primer: 5'-GGAGCTCCCTTTTCGTGAATG-3' } \\
\text { Reverse primer: 5'-AGGTAAGTGGTTGCCCATCAGA-3' } \\
\text { Probe: 5'-(FAM) CCAAGACAGGTCGCTCAGGGTCACA(TAMRA)-3' }\end{array}$ & 62 \\
\hline IL-6 & $\begin{array}{l}\text { Forward primer: 5'-TCCTACCCCAATTTCCAATGC-3' } \\
\text { Reverse primer: 5'-CCACAGTGAGGAATGTCCACAA-3' } \\
\text { Probe: 5'-(FAM) ATCTACTCGGCAAACCTAGTGCGTT(TAMRA)-3' }\end{array}$ & 62 \\
\hline$\beta$-actin & $\begin{array}{l}\text { Forward primer: 5'-ATGGTGGGAATGGGTCAGAAG-3' } \\
\text { Reverse primer: 5'-TCCATGTCGTCCCAGTTGGTA-3' } \\
\text { Probe: 5'-(FAM) TGACGAGGCCCAGAGCAAGAGAGGT(TAMRA)-3' }\end{array}$ & 62 \\
\hline
\end{tabular}

TNF- $\alpha$, tumor necrosis factor- $\alpha$; IL, interleukin.

sequences could be excluded; the negative control was designed according to the literature (12-14). The detailed sequences are shown in Table I. siRNA was synthesized by Zimmer (Shanghai) Medical International Trading Co., Ltd. (Shanghai, China).

Cell culture and transfection. RAW264.7 mouse macrophage cells (Shanghai Cell Bank of China Academy of Medical Sciences, Shanghai, China) were cultured in Dulbecco's modified Eagle's medium (DMEM) containing 10\% fetal bovine serum (Gibco; Life Technologies, Carlsbad, CA, USA) in a $37^{\circ} \mathrm{C}$ incubator with $5 \% \mathrm{CO}_{2}$. The RAW264.7 cells were inoculated in 24-well cell culture plates at a density of $8 \times 10^{4} /$ well and underwent transfection at $40 \%$ confluence. The final concentration of siRNA was $100 \mathrm{nM}$ (15). The transfection was performed using X-tremeGENE ${ }^{\mathrm{TM}}$ siRNA Transfection Reagent (Roche Applied Science, Indianapolis, IN, USA), according to the manufacturer's instructions. Three control groups were established: A blank control group, with an equal volume of medium; a transfection reagent control group and a negative control group. Each group was set-up in three repeated wells. A total of $5 \mathrm{~h}$ after the completion of the
siRNA transfection, lipopolysaccharide (LPS; Sigma-Aldrich, St. Louis, MO, USA) was added at a final concentration of $1 \mu \mathrm{g} / \mu \mathrm{l}$ to each well. Following $2 \mathrm{~h}$ of incubation, the cells and supernatant were collected for use in ELISA and reverse transcription-quantitative polymerase chain reaction (RT-qPCR) detection. The experiments were repeated three times.

$R T-q P C R$. Total RNA was extracted from the cells in each group using the Takara RNA extraction kit, in accordance with the manufacturer's instructions (Takara Biotechnology Co., Ltd., Dalian, China). Following extraction, $1 \mu \mathrm{g}$ total RNA was subjected to RT to obtain cDNA for qPCR analysis. The mouse TNF- $\alpha$, interleukin (IL)- $1 \beta$, IL- $6, \beta$-actin primers and Taqman probe were designed using an application of the Primer Express ${ }^{\mathrm{TM}}$ software v2.0 (Applied Biosystems, Foster City, CA, USA), and the sequences were as shown in Table II. The primers were synthesized by Shanghai Sangon Biotechnology Co., Ltd. (Shanghai, China), and the probes were synthesized by Takara Biotechnology Co., Ltd. The RT-qPCR system and reaction conditions were implemented based on the instructions of the PrimeScript ${ }^{\mathrm{TM}}$ RT-PCR kit (Takara Biotechnology Co., Ltd.). The qPCR was performed 
in the Rotor-Gene RG3500 PCR reaction instrument (Qiagen, Shanghai, China). The Ct value was automatically recorded by Rotor-Gene6 software. The relative expression levels of the TNF- $\alpha$, IL- $1 \beta$ and IL- 6 mRNA were calculated using the $2^{-\Delta \Delta \mathrm{Ct}}$ method: $\Delta \Delta \mathrm{Ct}=\left(\mathrm{Ct}_{\text {target gene }}-\mathrm{Ct}_{\text {reference gene }}\right)_{\text {test group }}-\left(\mathrm{Ct}_{\text {target }}\right.$ gene $\left.-\mathrm{Ct}_{\text {reference gene }}\right)_{\text {blank control group }}$. The inhibition rate of mRNA expression in each group was calculated using the following formula: $\mathrm{mRNA}$ inhibition rate $=[(1$-relative expression level of $\mathrm{mRNA}_{\text {treatment group }} / \mathrm{mRNA}$ relative expression negative control group $) / 1] \times 100 \%$.

ELISA. The supernatant of the cell culture in each group was used to detect the TNF- $\alpha$ content via the ELISA method, according to the kit manufacturer's instructions (Wuhan Boster Biological Technology, Ltd., Wuhan, China). The protein inhibition rate of TNF- $\alpha$ of each group was calculated using the following formula: Protein inhibition rate $=\left[\left(\mathrm{TNF}-\alpha_{\text {negative control }}\right.\right.$ group- $\left.\left.\mathrm{TNF}-\alpha_{\text {treatment group }}\right) / \mathrm{TNF}-\alpha_{\text {negative control group }}\right] \times 100 \%$.

Design of shRNA. Having screened for the high-efficiency siRNA sequence, the oligonucleotide sequence was designed and synthesized according to the requirements of the lentiviral vector construction. The 21-nucleotide oligonucleotide sequence in the forward single strand was forward and reverse combined, during which the loop structure was added to make the oligonucleotide forming the hairpin structure, with the restriction enzyme cutting site at the two ends. The sequence of the duplex structure was as follows: 5'-CCGGAAGAGGCT GAGACATAGGCACTTCAAGAGAGTGCCTATGTCTCA GCCTCTTTTTTTG-3'; 5'-AATTCAAAAAAAGAGGCT GAGACATAGGCACTCTCTTGAAGTGCCTATGTCTCA GCCTCTT-3'.

Construction of recombinant lentivirus shuttle plasmid. The double-stranded DNA was formed by oligonucleotides annealing at the reaction conditions of $90^{\circ} \mathrm{C}$ for $4 \mathrm{~min}, 70^{\circ} \mathrm{C}$ for $10 \mathrm{~min}$ and a slow decrease to room temperature. The PGCSIL-green fluorescent protein (GFP) vector (Shanghai Jikai Industry, Co., Shanghai, China) was double enzyme digested by $A g e \mathrm{I}$ and $E c o$ RI at $37^{\circ} \mathrm{C}$ for $1 \mathrm{~h}$, and gel electrophoretic recovery of the linear pGCSIL-GFP fragments was performed. The annealed, double-stranded DNA and linear pGCSIL-GFP fragments were connected using T4 ligase (Takara Biotechnology Co., Ltd.) at $4^{\circ} \mathrm{C}$ for $16 \mathrm{~h}$. The pGCSIL-GFP-shRNA connection products were used to transform DH5 $\alpha$ competent cells (Takara Biotechnology Co., Ltd.), and the transformed competent cells were then shifted into antibiotic LB medium containing ampicillin (Shanghai Solarbio Bioscience \& Technology Co., Ltd., Shanghai, China), at $37^{\circ} \mathrm{C}$ for $16 \mathrm{~h}$. A single colony was selected to undergo PCR. The PCR primers were as follows: Upstream, 5'-CCTATT TCCCATGATTCCTTCATA-3'; and downstream, 5'-GTA ATACGGTTATCCACGCG-3'. The PCR reaction conditions comprised initial denaturation at $94^{\circ} \mathrm{C}$ for $30 \mathrm{sec}$; denaturation at $94^{\circ} \mathrm{C}$ for $30 \mathrm{sec}$, annealing at $60^{\circ} \mathrm{C}$ for $30 \mathrm{sec}$ and extension at $72^{\circ} \mathrm{C}$ for $30 \mathrm{sec}\left(30\right.$ cycles); and then extension at $72^{\circ} \mathrm{C}$ for $6 \mathrm{~min}$. The PCR products were subjected to $2 \%$ agarose gel electrophoresis. Following the selection of the single colony and the agitation of the bacteria, the plasmid was extracted for sequencing.
Lentiviral packaging. 293T cells (Type Culture Collection of the Chinese Academy of Sciences, Shanghai, China) were cultured in DMEM containing $10 \%$ fetal bovine serum in a $37^{\circ} \mathrm{C}$ incubator with $5 \% \mathrm{CO}_{2}$. One day before transfection, the logarithmic growth phase cells were inoculated at a density of $6 \times 10^{8} / 1$ in $15-\mathrm{cm}$ cell culture dishes $(70-80 \%$ confluence at the time of transfection). At $2 \mathrm{~h}$ before transfection, the cell medium was changed to serum-free medium. The lentiviral shuttle plasmid, lentiviral packaging plasmid and transfection reagent Lipofectamine ${ }^{\mathrm{TM}} 2000$ (Invitrogen; Life Technologies) were mixed to form transfection complexes, which were co-transfected into $293 \mathrm{~T}$ cells. At $8 \mathrm{~h}$ after transfection, the medium was replaced with fresh medium containing $10 \%$ serum and the cells were then cultured for a further $48 \mathrm{~h}$, prior to the culture supernatant being collected, centrifuged at $4,000 \mathrm{x}$ g for $10 \mathrm{~min}$ and filtered with a $0.45-\mu \mathrm{M}$ filter. The concentrated vector, which was referred to as lentivirus-shTNF, was stored at $-80^{\circ} \mathrm{C}$ until use.

Determination of virus titer. The 293T cells that were used for virus transfection were inoculated in 96-well plates at a density of $4 \times 10^{4} /$ well and cultured in a $37^{\circ} \mathrm{C}$ incubator with $5 \%$ $\mathrm{CO}_{2}$ for $24 \mathrm{~h}$. A total of $90 \mu \mathrm{l}$ culture medium was removed and $90 \mu 1$ serial dilution of virus stock was added, prior to further culture for $24 \mathrm{~h}$ and the replacement of the medium. After $96 \mathrm{~h}$, the green fluorescence expression was observed under a fluorescence microscope. The wells in which $\sim 5$ fluorescent cells as well as the corresponding dilution ratio were recorded (fluorescent cells were counted independently by 2 specifically assigned individuals). The virus titer was calculated using the following formula: Virus titer $(\mathrm{TU} / \mu \mathrm{l})=$ number of fluorescent cells/corresponding dilution ratio.

Statistical analysis. The software SigmaStat 11.0 (Systat Software, Inc., San Jose, CA, USA) was used for data processing. Quantitative data are expressed as the mean \pm standard error of the mean; comparisons among the groups were performed using one-way analysis of variance, and the Dunnett's $t$-test was used for comparisons between the experimental groups and the control group. $\mathrm{P}<0.05$ was considered to indicate a statistically significant difference.

\section{Results}

Expression of TNF- $\alpha, I L-1 \beta$ and IL- $6 m R N A$. The relative mRNA expression levels of TNF- $\alpha$ in the siRNA1, siRNA2, siRNA3 and negative control groups were, respectively, $0.24 \pm 0.01,0.16 \pm 0.02$, $0.19 \pm 0.01$ and $0.95 \pm 0.02$. Significant differences were found in the expression levels between each group $(\mathrm{F}=531.3, \mathrm{P}<0.0001)$. As compared with the negative control group, the mRNA inhibition rates were $74.26,83.09$ and $79.93 \%$ for siRNA1, siRNA2 and siRNA3, respectively. The relative mRNA expression levels of IL-1 $\beta$ in the siRNA1, siRNA2, siRNA3 and negative control groups were, respectively, $0.93 \pm 0.04,0.93 \pm 0.02,0.92 \pm 0.02$ and $0.93 \pm 0.03$, and no significant differences were found among the groups $(\mathrm{F}=0.981, \mathrm{P}=0.9807)$. The relative mRNA expression levels of IL-6 in the siRNA1, siRNA2, siRNA3 and negative control groups were, respectively, $0.96 \pm 0.04,1 \pm 0.07,0.92 \pm 0.03$ and $0.94 \pm 0.01$, and no significant differences were found among the groups $(\mathrm{F}=0.739, \mathrm{P}=0.5867)$, as shown in Fig. 1 . 


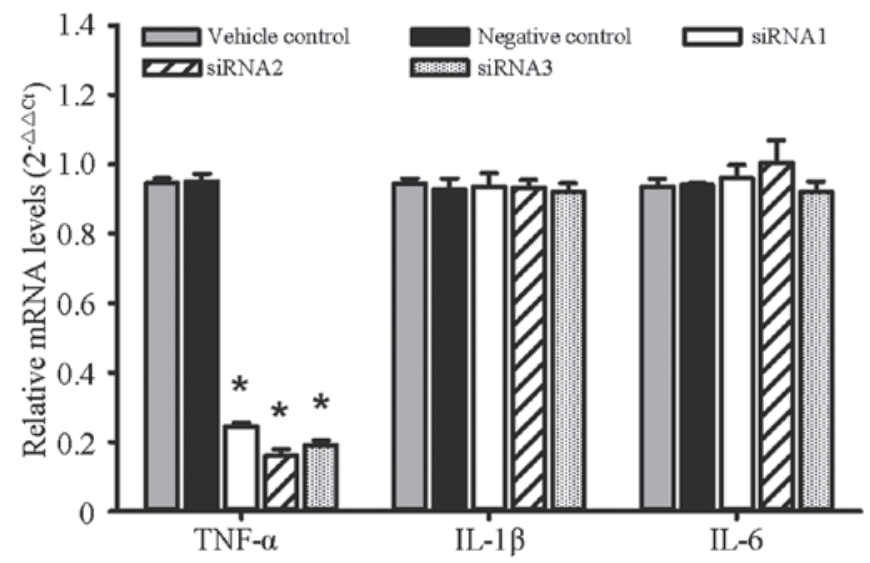

Figure 1. Relative mRNA expression levels of TNF- $\alpha$, IL- $\beta$ and IL-6 in RAW264.7 cells of different groups. Data are expressed as the mean \pm standard error of the mean. ${ }^{*} \mathrm{P}<0.05$ vs. negative control. TNF- $\alpha$, tumor necrosis factor- $\alpha$; IL, interleukin; siRNA, small interfering RNA.

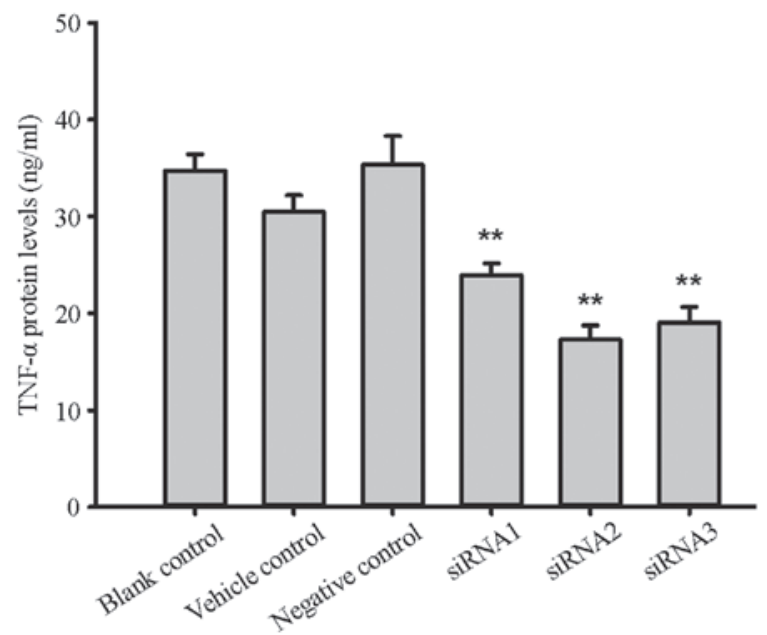

Figure 2. TNF- $\alpha$ protein expression levels of different RAW264.7 groups Data are expressed as the mean \pm standard error of the mean.* $\mathrm{P}<0.01$ vs. negative control. TNF- $\alpha$, tumor necrosis factor- $\alpha$; siRNA, small interfering RNA.

TNF- $\alpha$ protein expression. The protein expression levels of TNF- $\alpha$ in the siRNA1, siRNA2, siRNA3 and negative control groups were $23.95 \pm 1.21,17.27 \pm 1.46,19.07 \pm 1.57$ and $35.37 \pm 2.93 \mathrm{ng} / \mathrm{ml}$ respectively, and significant differences were found between the groups $(\mathrm{F}=18.1, \mathrm{P}=0.0006)$. Compared with the negative control, the TNF- $\alpha$ protein expression inhibition rates were $32.29,51.16$ and $46.08 \%$, respectively. The protein expression levels in the blank and reagent control groups were $34.75 \pm 1.67$ and $30.48 \pm 1.701 \mathrm{ng} / \mathrm{ml}$, respectively, and no significant difference was found compared with the levels in the negative control group $(\mathrm{F}=1.49, \mathrm{P}=0.30)$, as shown in Fig. 2.

$q P C R$. The recombinant lentiviral plasmid PCR amplification product was $343 \mathrm{bp}$, the empty-vector PCR product was $306 \mathrm{bp}$ and the insert fragment was $61 \mathrm{bp}$; these results were consistent with the expectation. It should ne noted that there were 4 restriction enzyme sites in the pGCSIL-GFP vector between the AgeI and EcoRI sites, with a total length of $24 \mathrm{bp}$;

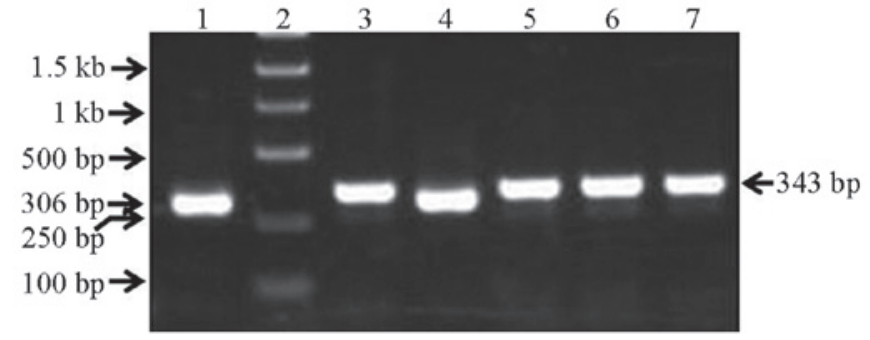

Figure 3. Electrophoresis map of the polymerase chain reaction products. Lane 1, non-constructed vector negative control; lane 2, Marker; lane 4, negative clone; lanes 3 and 5-7, positive clones.

therefore, the products were as follows: $306 \mathrm{bp}-24 \mathrm{bp}+$ insert fragment $=343 \mathrm{bp}$, as shown in Fig. 3 .

DNA sequencing. DNA sequencing revealed that the pGCSIL-GFP-shRNA sequencing reaction was interrupted, but the presence of an insertion sequence was indicated, as shown in Fig. 4.

Lentiviral packaging and identification. The lentiviral shuttle and packaging plasmids were co-transfected into the $293 \mathrm{~T}$ cells. After $48 \mathrm{~h}$, it was visible that cells were growing well, and the fluorescence expression was strong under the fluorescence microscope. After 96 h, it was observed under the fluorescence microscope that the number of fluorescent cells decreased as the dilution ratio increased. The lentiviral titer was calculated to be $2 \times 10^{6} \mathrm{TU} / \mu 1$, as shown in Fig. 5 .

\section{Discussion}

TNF- $\alpha$ is the key cytokine leading to inflammatory joint diseases (9); therefore, the aim of the present study was to construct RNAi lentiviral vectors targeting the mouse TNF- $\alpha$ gene, providing a basis for RNAi gene therapy. Developing an efficient interference fragment and effective gene transfer method is fundamental in RNAi gene therapy.

In this study, three pairs of siRNA targeting TNF- $\alpha$ were designed, synthesized and screened at the cellular level. RAW264.7 mouse macrophage cells are commonly used as inflammatory cell models, expressing high levels of TNF- $\alpha$ following stimulation by LPS $(16,17)$, and can thus be used for siRNA screening. Following the transfection of the siRNA into the RAW264.7 cells and the administration of the LPS stimulus, the RNAi gene silencing effect was detected at the mRNA and protein levels. The results showed that the expression inhibition of the three siRNAs on TNF- $\alpha$ at the mRNA and protein levels was significantly different compared with that in the control group; siRNA2 exhibited the highest inhibitory effect at both investigated levels and was selected as the highest silence efficiency interference sequence for follow-up study.

The inhibition of TNF- $\alpha$ expression was expected be accompanied by a decrease in the expression of IL- $1 \beta$, IL-6 and other inflammatory factors, as TNF- $\alpha$ can further induce the generation of IL-1 $\beta$ and IL-6; however, the results showed that RNAi targeting the TNF- $\alpha$ gene had no significant effect on the mRNA expression of IL-1 $\beta$ or IL- 6 . This may have 


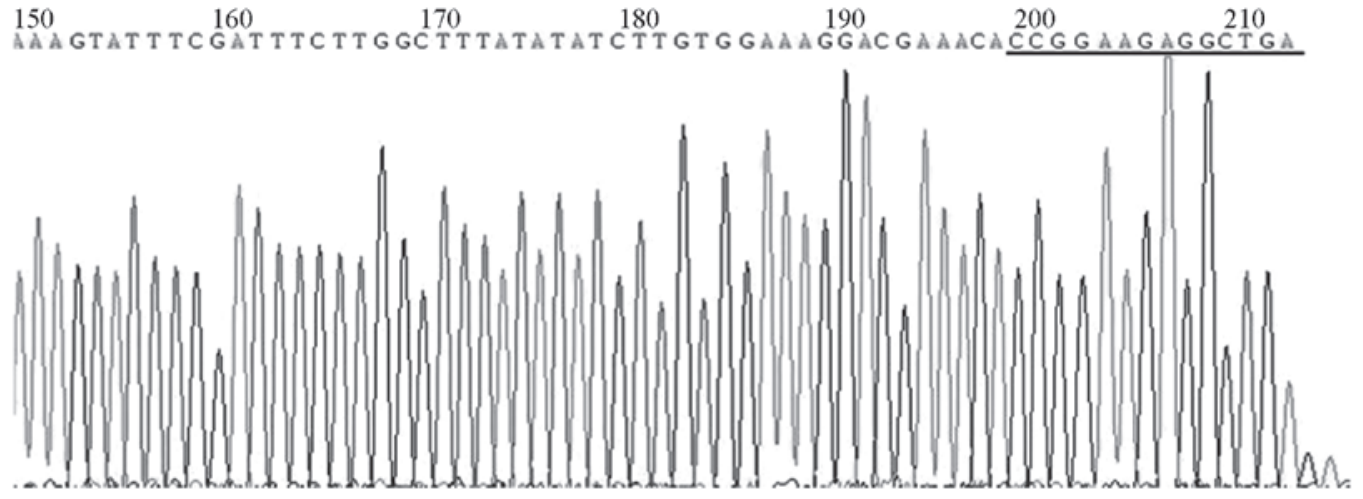

Figure 4. Recombinant plasmid DNA sequencing graph (part). The underlined region indicates the detected insertion sequence.

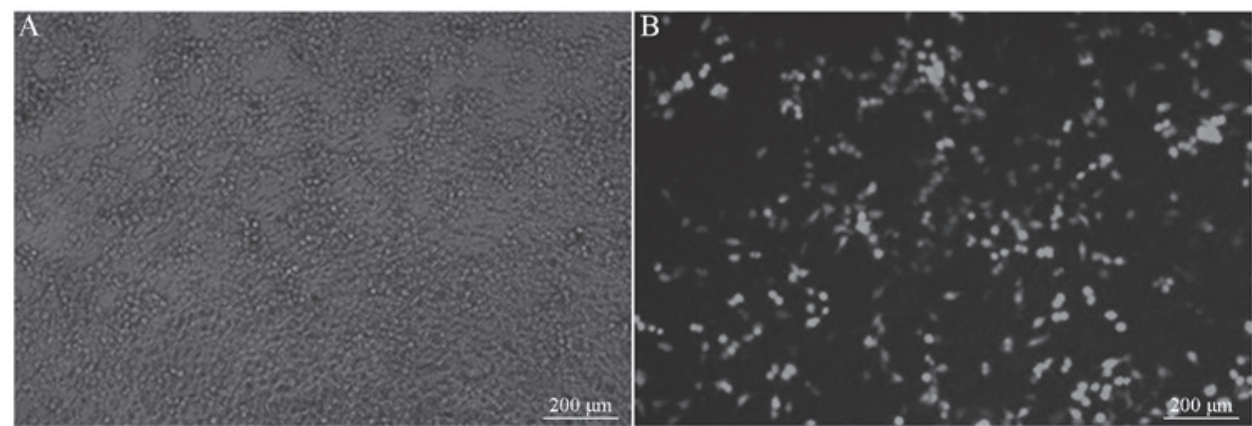

Figure 5. Green fluorescent protein expression of 293T cells transfected with lentiviral plasmids. (A) Light microscopy; (B) fluorescence microscopy (multiplicity of infection $=0.5$; scale bar $=200 \mu \mathrm{m}$ ).

been a result of the fact that, although the application of the siRNA inhibited the expression of TNF- $\alpha$, the inflammatory cell model was still in existence due to the LPS stimulation, and the combination of LPS and the RAW264.7 cell surface receptor was still able to induce the generation of IL-1 $\beta$ and IL- 6 via the activation of nuclear factor- $\kappa \mathrm{B}$. The results therefore showed the specificity of the RNAi.

In the present study, the siRNA was transfected into the RAW264.7 cells, which were then stimulated by LPS; $7 \mathrm{~h}$ after transfection, the gene silencing effect was observed. A study involving the J774.1 mouse macrophage cell line described similar results to those in the present study (15); however, the study reported that the gene silencing effect of siRNA was observed at the mRNA level $>24 \mathrm{~h}$ after transfection and at the protein level $>48 \mathrm{~h}$ after transfection.

Liposomes and electrotransfection are common methods of gene transfection; however, the target gene fragments following transfection are easily degraded and, following electrotransfection, cells have a low survival rate and low availability in clinical experiments $(18,19)$. Viral vectors, such as adenovirus, adeno-associated virus and lentiviral vectors, have been widely used in molecular biology; however, adenoviruses are difficult to transfect into monocytes (20). It has previously been shown that lentiviral vectors can be used in numerous types of cells that are difficult to transfect, including monocytes $(6-8,21)$. In addition, lentiviral vectors can result in the integration of the interference fragment of the target gene into the genome, enabling the long-term suppression of target gene expression. This is particularly advantageous for in vitro and in vivo experimental studies and, therefore, a lentiviral vector was selected for use in the RNAi in the present study.

In this study, the pGCSIL-GFP vector containing a U6 promoter was used as the interference plasmid, which enabled the sustained expression of shRNA in the host cells, as well as the concurrent expression of GFP. In the identification of the recombinant lentiviral shuttle plasmid PCR product, electrophoresis showed that a 61-bp target fragment was inserted in the positive clones. DNA sequencing only showed a partial insertion sequence, which may have been due to the readiness of shRNA to form a secondary structure $(22,23)$. PCR product electrophoresis and DNA sequencing determined that the recombination was successful. In addition to the pGCSIL-GFP vector, the recombinant lentivirus packaging system must contain a packaging vector with the other elements and capsid protein for lentiviral packaging. The use of $293 \mathrm{~T}$ cells as the virus packaging cells can produce high-titer virus particles, which can be used to detect the virus packaging effect and infection efficiency of target cells. The virus titer in the present study was found to be $2 \times 10^{6} \mathrm{TU} / \mu \mathrm{l}$, indicating usefulness for subsequent in vitro and in vivo experimental studies.

In conclusion, an RNAi lentiviral vector targeting the TNF- $\alpha$ gene was in constructed the present study; the vector construction was found to be successful and, following packaging and concentration, high-titer lentiviral vectors were obtained. The findings of this study provide a basis for subsequent experimental study of RNAi gene therapy targeting TNF- $\alpha$. 


\section{Acknowledgements}

This study was supported by the Scientific Research Award Fund of Shandong Province Outstanding Young Scientist.

\section{References}

1. Chen SY, Shiau AL, Li YT, Lin YS, Lee CH, Wu CL and Wang CR: Suppression of collagen-induced arthritis by intra-articular lentiviral vector-mediated delivery of Toll-like receptor 7 short hairpin RNA gene. Gene Ther 19: 752-760, 2012

2. Sakuma T, Barry MA and Ikeda Y: Lentiviral vectors: Basic to translational. Biochem J 443: 603-618, 2012.

3. Gouze E, Pawliuk R, Pilapil C, Gouze JN, Fleet C, Palmer GD, Evans $\mathrm{CH}$, Leboulch $\mathrm{P}$ and Ghivizzani SC: In vivo gene delivery to synovium by lentiviral vectors. Mol Ther 5: 397-404, 2002.

4. Lewis PF and Emerman M: Passage through mitosis is required for oncoretroviruses but not for the human immunodeficiency virus. J Virol 68: 510-516, 1994.

5. Naldini L, Blömer U, Gallay P, Ory D, Mulligan R, Gage FH, Verma IM and Trono D: In vivo gene delivery and stable transduction of nondividing cells by a lentiviral vector. Science 272 . 263-267, 1996 .

6. Wilson AA, Kwok LW, Porter EL, Payne JG, McElroy GS Ohle SJ, Greenhill SR, Blahna MT, Yamamoto K, Jean JC, et al Lentiviral delivery of RNAi for in vivo lineage-specific modulation of gene expression in mouse lung macrophages. Mol Ther 21: 825-833, 2013.

7. Wollebo HS, Woldemichaele B and White MK: Lentiviral transduction of neuronal cells. Methods Mol Biol 1078: 141-146, 2013

8. Houbracken I, Baeyens L, Ravassard P, Heimberg H and Bouwens L: Gene delivery to pancreatic exocrine cells in vivo and in vitro. BMC Biotechnol 12: 74, 2012.

9. Moelants EA, Mortier A, Van Damme J and Proost P: Regulation of TNF- $\alpha$ with a focus on rheumatoid arthritis. Immunol Cell Biol 91: 393-401, 2013.

10. Elbashir SM, Harborth J, Lendeckel W, Yalcin A, Weber K and Tuschl T: Duplexes of 21-nucleotide RNAs mediate RNA interference in cultured mammalian cells. Nature 411: 494-498, 2001.

11. Svoboda P: Off-targeting and other non-specific effects of RNAi experiments in mammalian cells. Curr Opin Mol Ther 9 248-257, 2007.

12. Lin X, Yu Y, Zhao H, Zhang Y, Manela J and Tonetti DA: Overexpression of PKCalpha is required to impart estradiol inhibition and tamoxifen-resistance in a T47D human breast cancer tumor model. Carcinogenesis 27: 1538-1546, 2006.
13. Qiu Z, Huang C, Sun J, Qiu W, Zhang J, Li H, Jiang T, Huang K and Cao J: RNA interference-mediated signal transducers and activators of transcription 3 gene silencing inhibits invasion and metastasis of human pancreatic cancer cells. Cancer Sci 98 1099-1106, 2007.

14. Ai Z, Yin L, Zhou X, Zhu Y, Zhu D, Yu Y and Feng Y: Inhibition of survivin reduces cell proliferation and induces apoptosis in human endometrial cancer. Cancer 107: 746-756, 2006.

15. Khoury M, Louis-Plence P, Escriou V, Noel D, Largeau C, Cantos C, Scherman D, Jorgensen C and Apparailly F: Efficient new cationic liposome formulation for systemic delivery of small interfering RNA silencing tumor necrosis factor alpha in experimental arthritis. Arthritis Rheum 54: 1867-1877, 2006.

16. Zhu ZG, Jin H, Yu PJ, Tian YX, Zhang JJ and Wu SG: Mollugin inhibits the inflammatory response in lipopolysaccharide-stimulated RAW264.7 macrophages by blocking the Janus kinase-signal transducers and activators of transcription signaling pathway. Biol Pharm Bull 36: 399-406, 2013.

17. Qureshi AA, Guan XQ, Reis JC, Papasian CJ, Jabre S, Morrison DC and Qureshi N: Inhibition of nitric oxide and inflammatory cytokines in LPS-stimulated murine macrophages by resveratrol, a potent proteasome inhibitor. Lipids Health Dis 11: 76, 2012.

18. Kusumawati A, Commes T, Liautard JP and Widada JS: Transfection of myelomonocytic cell lines: Cellular response to a lipid-based reagent and electroporation. Anal Biochem 269: 219-221, 1999.

19. Liao HS, Kodama T, Doi T, Emi M, Asaoka H, Itakura H and Matsumoto A: Novel elements located at -504 to -399 bp of the promoter region regulated the expression of the human macrophage scavenger receptor gene in murine macrophages. J Lipid Res 38: 1433-1444, 1997.

20. Wirtz S, Becker C, Blumberg R, Galle PR and Neurath MF Treatment of $\mathrm{T}$ cell-dependent experimental colitis in SCID mice by local administration of an adenovirus expressing IL-18 antisense mRNA. J Immunol 168: 411-420, 2002.

21. Lee JS, Hmama Z, Mui A and Reiner NE: Stable gene silencing in human monocytic cell lines using lentiviral-delivered small interference RNA. Silencing of the p110alpha isoform of phosphoinositide 3-kinase reveals differential regulation of adherence induced by 1alpha,25-dihydroxycholecalciferol and bacterial lipopolysaccharide. J Biol Chem 279: 9379-9388, 2004.

22. Guo Y, Liu J, Li YH, Song TB, Wu J, Zheng CX and Xue CF: Effect of vector-expressed shRNAs on hTERT expression. World J Gastroenterol 11: 2912-2915, 2005.

23. McIntyre GJ and Fanning GC: Design and cloning strategies for constructing shRNA expression vectors. BMC Biotechnol 6: 1,2006 . 